\title{
Psychological factors at work and musculoskeletal disorders: a one year prospective study
}

\author{
Joanna Bugajska $\cdot$ Dorota Żołnierczyk-Zreda • Anna Jędryka-Góral • \\ Robert Gasik • Katarzyna Hildt-Ciupińska • Marzena Malińska • \\ Sylwia Bedyńska
}

Received: 9 October 2012/ Accepted: 30 July 2013/Published online: 11 August 2013

(C) The Author(s) 2013. This article is published with open access at Springerlink.com

\begin{abstract}
The etiology of musculoskeletal disorders is complex, with physical and psychosocial working conditions playing an important role. This study aimed to determine the relationship between psychosocial work conditions, such as psychological job demands, decision latitude, social support and job insecurity and musculoskeletal complains (MSCs) and (repetitive strain injuries (RSIs) in a 1-year prospective study. The job content questionnaire, the Nordic musculoskeletal questionnaire and provocation tests were used to study 725 employees aged $20-70$ years. Pain in the lower back (58\% of subjects), neck (57\%), wrists/hands (47\%) and upper back (44\%) was most frequent. The carpal tunnel syndrome (CTS) $(33.6 \%)$, rotator cuff tendinitis $(15.4 \%)$, Guyon's canal syndrome $(13.4 \%)$, lateral epicondylitis $(7.6 \%)$, medial epicondylitis $(5.3 \%)$, tendinitis of forearm-wrist extensors $(7.8 \%)$ and tendinitis of forearm-wrist flexors $(7.3 \%)$ were the most frequent RSIs. Logistic analysis showed that increased psychological job demands statistically significantly increased the probability of lateral and medial epicondylitis, and increased control (decision latitude) statistically significantly decreased the risk of CTS. There was no relationship between job insecurity, social
\end{abstract}

J. Bugajska ( $ه) \cdot$ D. Żołnierczyk-Zreda · K. Hildt-Ciupińska · M. Malińska

Central Institute for Labour Protection-National Research

Institute (CIOP-PIB), Czerniakowska 16,

00-701 Warszawa, Poland

e-mail: jobug@ciop.pl

A. Jędryka-Góral · R. Gasik

Institute of Rheumatology, Warszawa, Poland

S. Bedyńska

Warsaw School of Social Sciences and Humanities (SWPS),

Warszawa, Poland support and the studied RSIs. Psychosocial factors at work predict prevalence of MSCs and RSIs, irrespectively of demographic factors, e.g., age or gender, and organizational and physical factors.

Keywords MSDs · Psychosocial factors ·

Work demands

\section{Introduction}

Maintaining work ability as long as possible and simultaneously the best health-related quality of life becomes a self-evident expectance of the society at large. Among occupationally active people, irrespective of their job type, some health problems occur more and more often and this tendency increases. Symptomatology of these problems might be different with repetitive strain injuries (RSIs) being one of the most common. Musculoskeletal complaints (MSCs), i.e., mainly regional pain in the locomotor system, also are often observed in that population. This means employees more and more frequently seek specialist rheumatic care.

The large body of literature focuses on MSDs, the synonym for RSIs, formerly also recognized under names of overload syndromes or overload injuries. The etiology of MSDs is complex, with occupational factors among the several causes conducive to the onset of those disorders. Physical factors related to the working environment and the way work is done such as body posture, forces exerted on the musculoskeletal system, repetitive movements, manual material handling, vibrations and microclimate are among the occupational factors that increase the risk of MSDs. Those factors are compounded by personal factors related to health and life style. 
Since the beginning of the 1990s, there has been increased interest in the role of occupational psychosocial factors in the onset of MSDs [1-4]. Researchers have so far focused on various groups of workers and occupational factors, and most frequently they referred to those highlighted by Karasek [5, 6] in his model of work-related stress, such as psychological demands and decision latitude, than extended by social support. According to this model, high psychological demands, low decision latitude and low social support are related to stress and diseases. However, the findings of the studies exploring the link between these psychosocial factors and MSDs are inconclusive, and most of them have focused on a limited body regions, such as neck and shoulder [1, 7-10] or low-back pain $[2,11,12]$.

Various pathomechanisms probably play a role in the aetiopathogenesis of MSCs. According to one theory, adverse psychosocial work factors increase physical load: high job demands result in increased exposure to effort over long work hours, few breaks at work and infrequent changes in posture. Van den Heuevel et al.'s [13] study supports this interpretation; it showed that the impact of psychosocial factors on the onset of complaints in the upper limb decreases with a decrease in physical work load.

Musculoskeletal pain can also develop irrespective of pathophysiological processes accompanied by tissue damage when (vulnerable or oversensitive) workers have such a perception of situations at work that they become aware of complaints that in less demanding conditions would have remained unnoticed [7, 14].

In addition to psychosocial factors, personal traits [15, 16] and coincidence of psychosocial factors and the demands of family life can also result in stress and an onset of MSCs.

This study aimed to determine the relationship between psychosocial factors at work, such as decision latitude, psychological job demands, social support and job insecurity, and the onset of MSCs and repetitive strain injury (RSI) in employees performing mental and physical work.

\section{Materials and methods}

\section{Organization of the study}

This was a prospective study. Its main principle consisted in examining twice, 12 months apart, the same group of employees. Employees reporting for periodic medical examinations participated in the study. Physicians, specialists in orthopedics, neurology and occupational medicine, who were familiar with the procedure of a physical examination of the musculoskeletal system according to the criteria document for evaluating the work-relatedness of upper-extremity musculoskeletal disorders [17], did the measurements. Participation in the study was voluntary. The Commission for Ethics in Scientific Studies at the Central Institute for Labour Protection-National Research Institute (CIOP-PIB) approved the protocol and the methods of the study. The study was performed in the different medium and large enterprises, in health, communications and industry sectors.

\section{Methods}

The job content questionnaire [5] was used to diagnose psychosocial working conditions. It describes physical and psychological working conditions. The study covered the most frequently analyzed work characteristics such as job demands, decision latitude, social support and job insecurity.

The Nordic musculoskeletal questionnaire [17] studied MSCs in nine regions of the body (the neck, shoulders, lower back, upper back, elbows, wrists/hands, hips/thighs, knees and ankles/feet) in the past 12 months and in the past 7 days.

RSI was investigated with provocation tests followed in accordance with Sluiter et al. [18] protocol. The following disorders were diagnosed: radiating neck pain, Guyon's canal syndrome, rotator cuff tendinitis, lateral epicondylitis, medial epicondylitis, carpal tunnel syndrome (CTS), tendinitis of forearm-wrist extensors and tendinitis of forearm-wrist flexors. The diagnosis of the syndrome was based on the positive results of at least one test.

\section{Statistical analysis}

Statistical analysis was done with SPSS version 18.0. The following tests were used:

- Chi-squared test to compare the prevalence of individual RSIs in measurements I and II and the prevalence of pain-related complaints in measurements I and II;

- hierarchic logistic regression analysis to predict prevalence of RSIs and pain-related complaints in individual regions of the body on the basis of variables defining psychosocial factors of the working environment. Variables obtained in measurements I and II were the dependent variables. Predicting variables obtained in measurement II made it possible to a greater degree to draw conclusions on the cause and effect. The dependent variables in the logistic analysis were as follows:

- complaints in nine regions of the body in the past 12 months, 
- at least one of the above mentioned RSIs.

Individual variables (age and gender), organizational and physical factors (working hours, repetitive work, force), were controlled in all analyses.

\section{Results}

Subjects' characteristics

There were 725 employees in measurement I and 542 $(74.8 \%)$ in measurement II. The remaining persons did not take part in measurement II for unrelated reasons (dismissal, change in the type of work, long sick leave, pregnancy, etc.). In both measurements, females were in majority $(77 \%)$. Range-age workers participated in study were $20-70$ years. We have not observed statistically significant differences in age between women and men. Table 1 lists their demographic and anthropometric characteristics.

The employees had various jobs: work that was mostly mental (office workers), work that was mostly physical (toolmakers, welders, seamstresses, TV assembly workers, workers assembling electric elements and packers in the cosmetic industry) and work that was a combination of both (drivers, driving instructors and nurses). In measurement I, $29.1 \%$ of the employees did mental work, $39.3 \%$ did physical work and $30.6 \%$ of employees did a combination of both. In measurement II, $33.2 \%$ did mental work, $37.1 \%$ did physical work and $29.7 \%$ a combination of both.

\section{$M S C s$}

The number of employees reporting in measurement II complaints in the neck, shoulders, upper back, lower back and ankles/feet both in the past 7 days and in the past 12 months was slightly lower than in measurement I. However, the number of subjects reporting in measurement II complaints in the elbows, wrists/hands, thighs and knees was slightly higher than in measurement I. Those differences were not statistically significant (Fig. 1).

\section{$R S I$}

Carpal tunnel syndrome was the most frequently diagnosed RSI in both measurements. The prevalence of all syndromes was lower in measurement II than in measurement I (Table 2). Those differences were statistically significant.

\section{Predictors}

Age and gender turned out to be the strongest predictors of RSI. With age, the probability of the onset of three RSIs
Table 1 Subjects' characteristics

\begin{tabular}{lcll}
\hline Parameter & Total (SD) & $\begin{array}{l}\text { Women } \\
(\mathrm{SD})\end{array}$ & Men (SD) \\
\hline Age (years) & & & \\
$\quad$ Measurement I & $42.8(9.9)$ & $42.5(9.9)$ & $43.3(10.3)$ \\
$\quad$ Measurement II & $43.6(10.1)$ & $43.6(9.8)$ & $44.3(10.3)$ \\
Tenure on the job (years) & & & \\
$\quad$ Measurement I & $15.3(11.2)$ & $14.5(10.8)$ & $17.6(12.1)$ \\
Measurement II & $16.1(11.2)$ & $15.5(10.9)$ & $17.9(11.9)$ \\
Total tenure (years) & & & \\
Measurement I & $20.9(10.5)$ & $20.1(10.2)$ & $23.0(11.1)$ \\
$\quad$ Measurement II & $21.8(10.6)$ & $21.7(10.3)$ & $23.8(11.2)$ \\
Body mass (kg) & & & \\
Measurement I & $71.9(14.3)$ & $67.5(12.4)$ & $84.6(11.7)$ \\
Measurement II & $71.2(14.1)$ & $67.3(12.1)$ & $85.5(11.7)$ \\
Body height (cm) & & & \\
Measurement I & $167.6(8.4)$ & $164.1(5.8)$ & $177.5(6.4)$ \\
Measurement II & $167.2(8.2)$ & $164.2(5.8)$ & $177.9(6.3)$ \\
Body mass index & & & \\
Measurement I & $25.5(4.2)$ & $25.1(4.3)$ & $26.9(3.7)$ \\
Measurement II & $25.4(4.1)$ & $24.9(4.1)$ & $26.9(3.6)$ \\
\hline
\end{tabular}

statistically significantly increased: lateral epicondylitis by $8 \%$ per year, medial epicondylitis by $11 \%$ and tendinitis of forearm-wrist extensor by $5 \%$ per year. In men, there was a statistically significantly lower probability of the onset of three RSIs: rotator cuff tendinitis by over $67 \%$ per year, lateral epicondylitis by $72 \%$ and CTS by $41 \%$ per year. Mental work demands turned out to be a significant predictor of three RSIs, lateral epicondylitis, medial epicondylitis and tendinitis of forearm-wrist flexors and decision latitude — of CTS (Table 3). Age and gender were also strong predictors of the onset of MSCs, both in the past 7 days and in the past 12 months (Tables 4, 5).

Psychological job demands have also been found to be a significant predictor of pain in the past 7 days in the shoulders, elbows, wrists/hands and ankles/feet; decision latitude and pain in the wrists/hands; and job insecurity was predictor of pain in the knees (Table 4). On the other hand, for complaints in the past 12 months, psychological job demands significantly predict pain in the shoulders; decision latitude predicts pain in the upper back; job insecurity significantly predicts pain in the knees; and social support predicts pain in the neck and ankles/feet (Table 5).

\section{Discussion}

The problem of the prevalence of musculoskeletal pain (MSCs) and RSI, which the working environment can cause, is rarely discussed in the literature on rheumatology. 
Fig. 1 Comparison of the prevalence of musculoskeletal complaints in 2 measurements

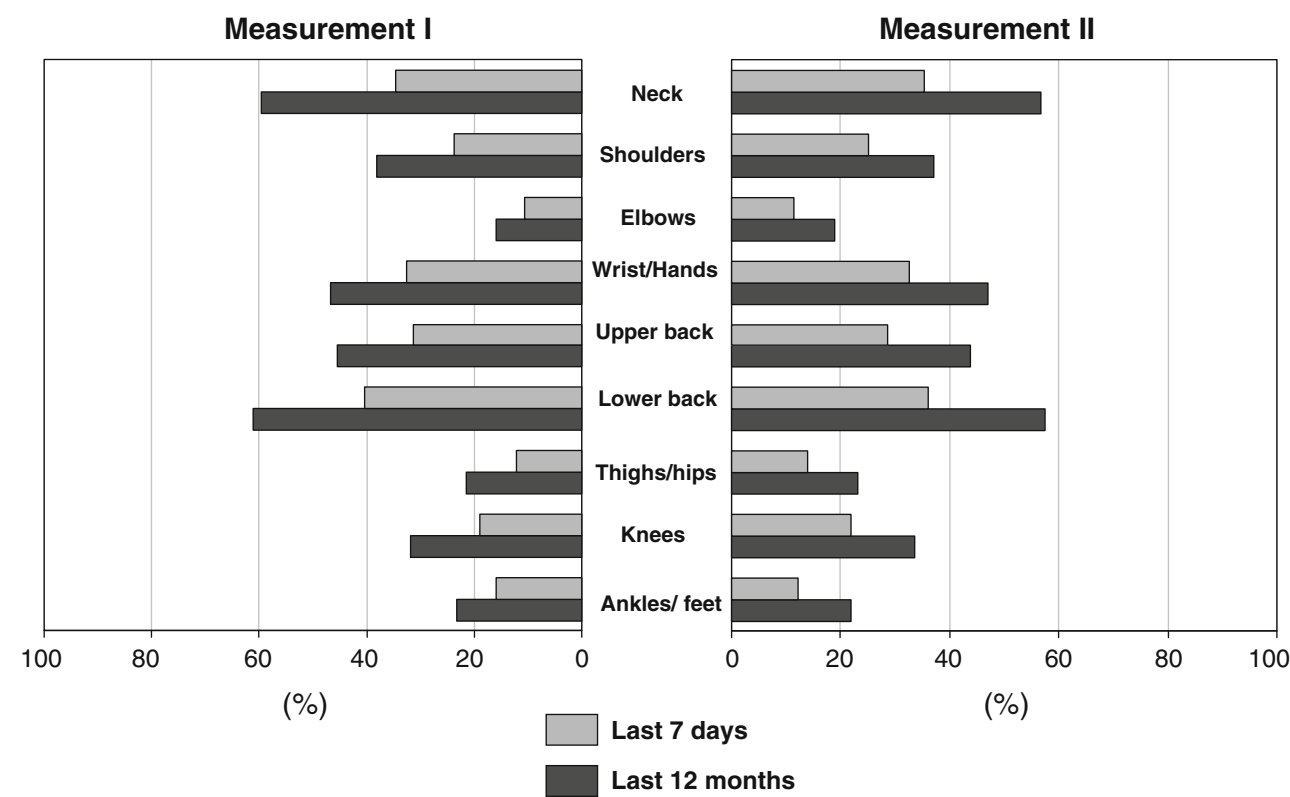

Table 2 The prevalence of repetitive strain injuries in 2 measurements

\begin{tabular}{lcccc}
\hline Parameter & $\begin{array}{l}\text { Total } \\
(\%)\end{array}$ & $\begin{array}{l}\text { Women } \\
(\%)\end{array}$ & $\begin{array}{l}\text { Men } \\
(\%)\end{array}$ & $p$ \\
\hline Rotator cuff tendinitis & & & & \\
$\quad$ Measurement I & 22.5 & 23.4 & 19.8 & 0.52 \\
$\quad$ Measurement II & 15.4 & 18.6 & 6.0 & 0.001 \\
Lateral epicondylitis & & & & \\
$\quad$ Measurement I & 12.2 & 15.0 & 4.3 & 0.002 \\
$\quad$ Measurement II & 7.6 & 9.0 & 3.4 & 0.05 \\
Medial epicondylitis & & & & \\
$\quad$ Measurement I & 7.2 & 8.7 & 5.2 & 0.31 \\
$\quad$ Measurement II & 5.3 & 6.0 & 3.4 & 0.34 \\
Carpal tunnel syndrome & & & & \\
$\quad$ Measurement I & 49.2 & 55.0 & 32.8 & 0.000 \\
$\quad$ Measurement II & 33.6 & 81.5 & 24.1 & 0.01 \\
Guyon's canal syndrome & & & & \\
$\quad$ Measurement I & 24.1 & 26.4 & 17.2 & 0.06 \\
$\quad$ Measurement II & 13.4 & 12.9 & 14.7 & 0.63 \\
Tendinitis of forearm-wrist & & & & \\
$\quad$ extensors & & & & \\
$\quad \begin{array}{l}\text { Measurement I } \\
\text { Measurement II }\end{array}$ & 8.9 & 9.9 & 6.0 & 0.26 \\
Tendinitis of forearm-wrist & & 9.0 & 4.3 & 0.11 \\
$\quad$ flexors & & & & \\
$\quad \begin{array}{l}\text { Measurement I } \\
\text { Measurement II }\end{array}$ & 71.1 & 11.4 & 10.3 & 0.86 \\
\hline & & 7.8 & 6.0 & 0.68 \\
\hline
\end{tabular}

However, this is an increasing clinical problem, and thus, rheumatologists should be made aware of it.

Studies published over 10 years old estimated that MSCs were prevalent in $\sim 15 \%$ of workers $[19,20]$. In a later study, with 869 workers from various occupational groups (manual handlers, delivery drivers, technicians, customer services, computer operators and general office staff), the prevalence of complaints was higher. Thirty-four percent of subjects reported pain-related complaints in the neck, $35 \%$ in the shoulders, $17 \%$ in the elbows and $35 \%$ in the wrists/ hands [21]. According to Walker-Bone et al.'s [22] questionnaire survey, almost $20 \%$ of 6,055 persons complained of pain in the neck and in the upper limbs. According to Roquelaure et al. [23], over $50 \%$ of 2,685 subjects reported MSCs. Pain-related complaints are also common in computer operators. According to Sillanpaa et al. [24], $63 \%$ of them reported pain in the neck, $24 \%$ in the shoulders, $18 \%$ in the elbows, $35 \%$ in the forearms and $16 \%$ in the back. According to Bugajska et al.'s [25] Polish study 14-64\% of women and 13-55\% of men performing repetitive tasks reported pain in different parts of the body. Women most frequently reported complaints in all the regions of the body that were studied. Lam and Thurstone [26] and de Zwart et al. [27] confirmed those results. Our study's results showed that the most common complaints were those in the lower back (58\% of subjects), the neck (57\%), the wrists/ hands $(47 \%)$ and the upper back $(44 \%)$.

It is interesting that in measurement II, after 12 months, there were generally fewer complaints of pain in individual regions of the body; there were fewer RSIs, too. The time factor usually plays a negative role in rheumatic disorders: the patient's condition deteriorates with time. In this case, the reverse was true. It is possible that workers whose health significantly deteriorated did not participate in measurement II. This is the so-called healthy worker effect.

MSCs are often temporary, and they are a reaction to short-term excessive musculoskeletal load. They disappear 
Table 3 Relationship between psychosocial factors and selected repetitive strain injuries (hierarchic logistic regression analysis)

\begin{tabular}{|c|c|c|c|c|c|c|c|}
\hline \multirow{2}{*}{$\begin{array}{l}\text { Independent } \\
\text { variable }\end{array}$} & \multicolumn{7}{|c|}{ Repetitive strain injury } \\
\hline & $\begin{array}{l}\text { Rotator cuff } \\
\text { tendinitis }\end{array}$ & $\begin{array}{l}\text { Lateral } \\
\text { epicondylitis }\end{array}$ & $\begin{array}{l}\text { Medial } \\
\text { epicondylitis }\end{array}$ & $\begin{array}{l}\text { Carpal tunnel } \\
\text { syndrome }\end{array}$ & $\begin{array}{l}\text { Guyon's canal } \\
\text { syndrome }\end{array}$ & $\begin{array}{l}\text { Tendinitis of } \\
\text { forearm-wrist } \\
\text { extensors }\end{array}$ & $\begin{array}{l}\text { Tendinitis of } \\
\text { forearm-wrist } \\
\text { flexors }\end{array}$ \\
\hline \multicolumn{8}{|l|}{ Age } \\
\hline OR & 1.025 & 1.084 & 1.106 & 0.988 & 0.978 & 1.050 & 1.019 \\
\hline$p$ & 0.103 & 0.001 & 0.001 & 0.318 & 0.156 & 0.024 & 0.371 \\
\hline $95 \% \mathrm{CI}$ & $0.995-1.056$ & $1.035-1.136$ & $1.043-1.172$ & $0.966-1.011$ & $0.948-1.009$ & $1.007-1.095$ & $0.978-1.061$ \\
\hline \multicolumn{8}{|l|}{ Gender } \\
\hline OR & 0.335 & 0.282 & 0.542 & 0.588 & 1.151 & 0.461 & 0.758 \\
\hline$p$ & 0.011 & 0.050 & 0.357 & 0.052 & 0.684 & 0.173 & 0.577 \\
\hline $95 \% \mathrm{CI}$ & $0.144-0.777$ & $0.079-0.998$ & $0.148-1.994$ & $0.344-1.004$ & $0.585-2.263$ & $0.152-1.403$ & $0.287-2.005$ \\
\hline \multicolumn{8}{|c|}{ Decision latitude } \\
\hline OR & 0.986 & 1.015 & 0.978 & 0.974 & 1.025 & 0.983 & 1.010 \\
\hline$p$ & 0.386 & 0.537 & 0.417 & 0.037 & 0.167 & 0.451 & 0.666 \\
\hline $95 \% \mathrm{CI}$ & $0.954-1.018$ & $0.968-1.065$ & $0.926-1.033$ & $0.950-0.998$ & $0.990-1.060$ & $0.940-1.028$ & $0.965-1.057$ \\
\hline \multicolumn{8}{|c|}{ Mental job demands } \\
\hline OR & 1.050 & 1.102 & 1.103 & 1.001 & 0.996 & 1.073 & 1.103 \\
\hline$p$ & 0.092 & 0.017 & 0.038 & 0.961 & 0.893 & 0.069 & 0.013 \\
\hline $95 \% \mathrm{CI}$ & $0.992-1.110$ & $1.017-1.194$ & $1.005-1.209$ & $0.957-1.047$ & $0.935-1.060$ & $0.995-1.158$ & $1.021-1.192$ \\
\hline \multicolumn{8}{|l|}{ Job insecurity } \\
\hline OR & 1.122 & 0.922 & 0.963 & 0.988 & 1.183 & 1.194 & 1.215 \\
\hline$p$ & 0.233 & 0.595 & 0.828 & 0.873 & 0.095 & 0.173 & 0.129 \\
\hline $95 \% \mathrm{CI}$ & $0.929-1.355$ & $0.685-1.242$ & $0.687-1.350$ & $0.847-1.151$ & $0.971-1.442$ & $0.925-1.541$ & $0.945-1.564$ \\
\hline \multicolumn{8}{|c|}{ Social support } \\
\hline OR & 1.003 & 1.053 & 1.084 & 1.038 & 1.003 & 1.121 & 1.060 \\
\hline$p$ & 0.952 & 0.441 & 0.304 & 0.341 & 0.957 & 0.101 & 0.395 \\
\hline $95 \% \mathrm{CI}$ & $0.911-1.104$ & $0.923-1.203$ & $0.929-1.266$ & $0.962-1.120$ & $0.903-1.114$ & $0.978-1.285$ & $0.927-1.212$ \\
\hline \multicolumn{8}{|c|}{ Physical job demands } \\
\hline OR & 1.232 & 1.007 & 0.744 & 1.307 & 0.735 & 0.893 & 0.837 \\
\hline$p$ & 0.211 & 0.974 & 0.268 & 0.036 & 0.074 & 0.595 & 0.427 \\
\hline $95 \% \mathrm{CI}$ & $0.889-1.707$ & $0.666-1.523$ & $0.441-1.255$ & $1.018-1.677$ & $0.524-1.030$ & $0.588-1.356$ & $0.540-1.298$ \\
\hline
\end{tabular}

once the effort stops, so their prevalence in workers was higher than the prevalence of RSIs. According to Roquelaure et al. [23], over $50 \%$ of 2,685 employees reported complaints of nonspecific MSCs, whereas $13 \%$ of them were clinically diagnosed with at least one RSI. Similarly, in Walker-Bone et al.'s [2] study, only $\sim 20 \%$ of persons with musculoskeletal pain had clinical bases for diagnosing one of the 11 defined RSIs.

In the present study, too, RSIs diagnosed on the basis of provocation tests were less frequent than pain-related complaints. CTS, diagnosed in $33.6 \%$ of the employees, was the most common one, followed by rotator cuff tendinitis in $15.4 \%$, Guyon's canal syndrome in $13.4 \%$, lateral epicondylitis in $7.6 \%$, medial epicondylitis in $5.3 \%$, tendonitis of forearm-wrist extensors in $7.8 \%$ and tendinitis of forearm-wrist flexors in $7.3 \%$ of the subjects.
We also observed statistically significant differences between women and men in prevalence of CTS and lateral epicondylitis, consequently occurred in both measurements. This finding is in line with above mentioned outcome showing that women more frequently report the musculoskeletal complains.

We are aware that the number of occurrences of MSC and RSI in our studies is high; it would certainly be lower if we had confirmed this using objective diagnostic methods. About $70 \%$ of worker in our study performed work that was mostly physical (toolmakers, welders, seamstresses, TV assembly workers, workers assembling electric elements and packers in the cosmetic industry) and work that was a combination of both (drivers, driving instructors and nurses). In the above mentioned occupations, an increased risk of MSD might occur. Nevertheless, the results 
Table 4 Relationship between musculoskeletal complaints experienced in the past 7 days and selected psychosocial factors (hierarchic logistic regression analysis)

\begin{tabular}{|c|c|c|c|c|c|c|c|c|c|}
\hline \multirow{2}{*}{$\begin{array}{l}\text { Independent } \\
\text { variable }\end{array}$} & \multicolumn{9}{|c|}{ Subjective complaints in the past 7 days } \\
\hline & Neck & Shoulders & Elbows & Wrists/hands & $\begin{array}{l}\text { Upper } \\
\text { back }\end{array}$ & $\begin{array}{l}\text { Lower } \\
\text { back }\end{array}$ & $\begin{array}{l}\text { One/both } \\
\text { thighs/hips }\end{array}$ & $\begin{array}{l}\text { One/both } \\
\text { knees }\end{array}$ & $\begin{array}{l}\text { One/both } \\
\text { ankles/feet }\end{array}$ \\
\hline \multicolumn{10}{|l|}{ Age } \\
\hline OR & 1.00 & 1.02 & 1.04 & 1.01 & 0.99 & 1.01 & 1.05 & 1.03 & 1.05 \\
\hline$p$ & 0.58 & 0.14 & 0.03 & 0.20 & 0.43 & 0.45 & 0.00 & 0.02 & 0.01 \\
\hline $95 \% \mathrm{CI}$ & $0.98-1.03$ & 0.99-1.04 & $1.00-1.08$ & $0.99-1.04$ & $0.96-1.01$ & $0.98-1.03$ & $1.02-1.09$ & $1.00-1.06$ & $1.01-1.09$ \\
\hline \multicolumn{10}{|l|}{ Gender } \\
\hline OR & 0.45 & 0.71 & 1.30 & 0.84 & 0.48 & 0.82 & 0.76 & 1.22 & 1.43 \\
\hline$p$ & 0.00 & 0.28 & 0.51 & 0.54 & 0.02 & 0.45 & 0.48 & 0.50 & 0.35 \\
\hline $95 \% \mathrm{CI}$ & $0.26-0.80$ & $0.39-1.31$ & $0.59-2.84$ & $0.47-1.48$ & $0.26-0.88$ & $0.49-1.38$ & $0.36-1.61$ & $0.69-2.16$ & $0.67-3.07$ \\
\hline \multicolumn{10}{|c|}{ Decision latitude } \\
\hline OR & 1.00 & 0.97 & 0.97 & 0.96 & 0.99 & 0.99 & 0.98 & 1.00 & 0.98 \\
\hline$p$ & 0.72 & 0.08 & 0.21 & 0.00 & 0.63 & 0.62 & 0.30 & 0.99 & 0.28 \\
\hline $95 \% \mathrm{CI}$ & $0.98-1.03$ & $0.95-1.00$ & $0.94-1.01$ & $0.93-0.98$ & $0.96-1.02$ & $0.97-1.02$ & $0.95-1.01$ & $0.97-1.03$ & $0.94-1.02$ \\
\hline \multicolumn{10}{|c|}{ Mental job demands } \\
\hline OR & 1.02 & 1.07 & 1.08 & 1.11 & 1.04 & 0.98 & 1.00 & 1.03 & 1.10 \\
\hline$p$ & 0.35 & 0.00 & 0.02 & 0.00 & 0.10 & 0.43 & 0.92 & 0.19 & 0.00 \\
\hline $95 \% \mathrm{CI}$ & $0.97-1.07$ & $1.02-1.13$ & $1.01-1.16$ & $1.06-1.17$ & $0.99-1.09$ & $0.94-1.03$ & $0.94-1.06$ & $0.98-1.09$ & $1.03-1.17$ \\
\hline \multicolumn{10}{|c|}{ Job insecurity } \\
\hline OR & 0.99 & 1.11 & 1.24 & 1.18 & 1.02 & 0.97 & 0.98 & 0.95 & 1.04 \\
\hline$p$ & 0.87 & 0.21 & 0.45 & 0.03 & 0.75 & 0.74 & 0.88 & 0.57 & 0.74 \\
\hline $95 \% \mathrm{CI}$ & $0.85-1.15$ & $0.94-1.30$ & $1.00-1.53$ & $1.01-1.38$ & $0.87-1.20$ & $0.84-1.13$ & $0.80-1.21$ & $0.80-1.13$ & $0.84-1.29$ \\
\hline \multicolumn{10}{|c|}{ Social support } \\
\hline OR & 0.97 & 1.06 & 1.09 & 1.08 & 0.97 & 0.95 & 0.93 & 0.99 & 0.98 \\
\hline$p$ & 0.40 & 0.16 & 0.15 & 0.06 & 0.44 & 0.18 & 0.20 & 0.76 & 0.71 \\
\hline $95 \% \mathrm{CI}$ & $0.89-1.04$ & $0.97-1.15$ & $0.97-1.22$ & $0.99-1.17$ & $0.89-1.05$ & $0.88-1.02$ & $0.84-1.03$ & $0.90-1.07$ & $0.87-1.09$ \\
\hline \multicolumn{10}{|c|}{ Physical job demands } \\
\hline OR & 0.98 & 1.29 & 1.46 & 1.56 & 1.36 & 1.12 & 0.86 & 0.99 & 1.44 \\
\hline$p$ & 0.92 & 0.07 & 0.05 & 0.00 & 0.02 & 0.34 & 0.38 & 0.93 & 0.05 \\
\hline $95 \% \mathrm{CI}$ & $0.77-1.27$ & $0.98-1.69$ & $0.99-2.13$ & $1.20-2.02$ & $1.04-1.77$ & $0.88-1.44$ & $0.61-1.21$ & $0.74-1.31$ & $1.00-2.06$ \\
\hline
\end{tabular}

represent an actual problem faced in the occupational environment, and we claim that each case of employee musculoskeletal complaint needs observation and often modification of work performance and, possibly, even specialist consultation and treatment.

An increase in those complaints in employees performing mental work inspired researchers to look into the working environment for causes of MSCs other than physical factors. They focused on the psychosocial factors at work which, independently or in an interaction with physical factors, could be the cause. In our study, we also found the significant impact of physical factors on prevalence on MSDs (wrist/hands and upper back) and RSI (Carpal Tunnel Syndrome). Therefore, the combined effect of psychosocial and physical factors is also likely to occur and should be considered in the further analysis of our data.
Earlier literature on the subject showed a positive relationship between work-related stress and prevalence of MSDs, especially in the neck [9]. Most studies pointed to high psychological job demands as a source of psychosocial stress in people with those complaints. There is also proof that low decision latitude, understood as workers' influence on their work, is also responsible for pain-related complaints in the upper section of the spine. According to critics of those studies, because they are cross-sectional and not longitudinal, it is impossible to unequivocally state that those psychosocial job conditions cause MSCs. Moreover, conclusions from those studies are difficult to generalize because of the varied ways of conceptualizing psychosocial job characteristics and the tools they were measured with.

This study aimed to avoid the methodological weaknesses of previous studies. Firstly, it was longitudinal, and 
Table 5 Relationship between limitations in activity related to complaints in the past 12 months and selected psychosocial factors (hierarchic logistic regression analysis)

\begin{tabular}{|c|c|c|c|c|c|c|c|c|c|}
\hline \multirow{2}{*}{$\begin{array}{l}\text { Independent } \\
\text { variable }\end{array}$} & \multicolumn{9}{|c|}{ Subjective complaints in the past 12 months } \\
\hline & Neck & Shoulders & Elbows & Wrists/hands & $\begin{array}{l}\text { Upper } \\
\text { back }\end{array}$ & $\begin{array}{l}\text { Lower } \\
\text { back }\end{array}$ & $\begin{array}{l}\text { One/both } \\
\text { thighs/hips }\end{array}$ & $\begin{array}{l}\text { One/both } \\
\text { knees }\end{array}$ & $\begin{array}{l}\text { One/both } \\
\text { ankles/feet }\end{array}$ \\
\hline \multicolumn{10}{|l|}{ Age } \\
\hline OR & 1.03 & 1.02 & 1.05 & 1.01 & 1.03 & 1.03 & 1.05 & 1.04 & 1.03 \\
\hline$p$ & 0.04 & 0.12 & 0.02 & 0.38 & 0.06 & 0.03 & 0.01 & 0.01 & 0.07 \\
\hline $95 \% \mathrm{CI}$ & $1.00-1.05$ & $0.99-1.05$ & $1.01-1.09$ & $0.98-1.04$ & $1.00-1.05$ & $1.00-1.05$ & $1.01-1.08$ & $1.01-1.07$ & $1.00-1.07$ \\
\hline \multicolumn{10}{|l|}{ Gender } \\
\hline OR & 0.33 & 0.46 & 1.08 & 0.43 & 0.56 & 0.78 & 0.38 & 0.88 & 1.36 \\
\hline$p$ & 0.00 & 0.05 & 0.86 & 0.02 & 0.10 & 0.40 & 0.05 & 0.70 & 0.40 \\
\hline $95 \%$ CI & $0.16-0.67$ & $0.21-1.01$ & $0.45-2.60$ & $0.21-0.88$ & $0.28-1.13$ & $0.45-1.38$ & $0.14-1.02$ & $0.46-1.69$ & $0.65-2.84$ \\
\hline \multicolumn{10}{|c|}{ Decision latitude } \\
\hline OR & 1.00 & 0.98 & 0.98 & 0.98 & 0.96 & 0.98 & 0.98 & 0.98 & 0.98 \\
\hline$p$ & 0.88 & 0.23 & 0.52 & 0.14 & 0.01 & 0.24 & 0.30 & 0.29 & 0.34 \\
\hline $95 \%$ CI & $0.97-1.03$ & $0.95-1.01$ & $0.94-1.03$ & $0.95-1.01$ & $0.93-0.99$ & $0.96-1.01$ & $0.94-1.02$ & $0.95-1.01$ & $0.95-1.02$ \\
\hline \multicolumn{10}{|c|}{ Mental job demands } \\
\hline OR & 1.00 & 1.04 & 1.07 & 1.08 & 1.03 & 1.02 & 1.03 & 1.05 & 1.08 \\
\hline$p$ & 0.91 & 0.12 & 0.07 & 0.00 & 0.27 & 0.41 & 0.29 & 0.08 & 0.01 \\
\hline $95 \%$ CI & $0.97-1.03$ & $1.00-1.10$ & $0.99-1.15$ & $1.03-1.14$ & $0.98-1.09$ & $0.97-1.07$ & $0.97-1.10$ & $0.99-1.11$ & $1.02-1.16$ \\
\hline \multicolumn{10}{|c|}{ Job insecurity } \\
\hline OR & 0.94 & 0.14 & 1.01 & 1.08 & 0.97 & 0.97 & 1.05 & 0.77 & 1.00 \\
\hline$p$ & 0.50 & 0.15 & 0.92 & 0.38 & 0.78 & 0.70 & 0.67 & 0.01 & 0.95 \\
\hline $95 \% \mathrm{CI}$ & $0.79-1.12$ & $0.95-1.37$ & $0.79-1.29$ & $0.91-1.28$ & $0.82-1.16$ & $0.83-1.36$ & $0.84-1.30$ & $0.63-0.95$ & $0.82-1.23$ \\
\hline \multicolumn{10}{|c|}{ Social support } \\
\hline OR & 0.90 & 1.02 & 0.99 & 0.95 & 0.96 & 0.97 & 0.93 & 0.97 & 0.87 \\
\hline$p$ & 0.02 & 0.70 & 0.90 & 0.25 & 0.47 & 0.48 & 0.22 & 0.49 & 0.01 \\
\hline $95 \% \mathrm{CI}$ & $0.82-0.99$ & $0.92-1.12$ & $0.87-1.13$ & $0.86-1.04$ & $0.88-1.06$ & $0.89-1.05$ & $0.83-1.04$ & $0.88-1.06$ & $0.77-0.97$ \\
\hline \multicolumn{10}{|c|}{ Physical job demands } \\
\hline OR & 1.23 & 1.21 & 1.11 & 1.57 & 1.40 & 1.03 & 1.07 & 0.87 & 1.15 \\
\hline$p$ & 0.14 & 0.23 & 0.61 & 0.00 & 0.02 & 0.84 & 0.70 & 0.38 & 0.41 \\
\hline $95 \% \mathrm{CI}$ & $0.93-1.64$ & $0.88-1.66$ & $0.74-1.68$ & $1.18-2.09$ & $1.04-1.87$ & $0.79-1.33$ & $0.75-1.53$ & $0.65-1.18$ & $0.82-1.61$ \\
\hline
\end{tabular}

it was conducted twice, one year apart, each time considering symptoms in the past 12 months and in the past 7 days. The methodology of this study increases the power of the cause-and-effect predictions. Secondly, the research assumptions were based on Karasek's conception, which is well established in the psychology of stress; it points to three basic dimensions of stress: psychological job demands, decision latitude and social support [27]. The study also considered the authors' latest modification of this conception, which consists in introducing another important source of stress at work into the model, i.e., job insecurity. In previous studies, on the relationship between psychosocial work characteristics and MSCs, not enough attention was devoted to this currently common threat. In the present study, job insecurity turned out to be a significant positive predictor of complaints related to the region of the elbows and wrists reported in the past 12 months and in the past 7 days. The results confirm the correctness of considering that psychosocial variable in predicting MSCs.

This study also proved that the other classic dimensions of Karasek's model really predict the prevalence of MSCs. Psychological job demands turned out to be the strongest one. They caused a significant increase in complaints in the elbows and wrists, and ankles/feet in the past 12 months and in the elbows, wrists, ankles/feet and shoulders in the past 7 days. The importance of psychological job demands in the pathogenesis of MSDs has also been confirmed by the results that show that they significantly contribute to the development of lateral epicondylitis and medial 
epicondylitis. The present results related to psychological job demands thus confirm the results of other studies [12, 13].

This study also showed low decision latitude as another predictor of MSCs; the lower the decision latitude, the stronger the short- and long-term complaints in the wrists/ hands, i.e., in the past 7 days and in the past 12 months. Moreover, low job decision latitude coincided with the prevalence of CTS. It should be pointed out that the present results are among the first in the literature that prove that long-term low decision latitude, understood as workers' lack of influence over the pace of work and breaks at work, is important for the occurrence of MSCs and their developing into RSIs. This finding is in step with other studies $[12,27-32]$. Social support turned out to be the weakest predictor of the complaints in the current study. Low social support at work caused an increase in complaints of pain in the region of the neck only. This is so probably because the effect of this occupational stressor is very nonspecific.

All individual (e.g., age and gender), organizational and physical variables (working hours, repetitive work, force), which are considered as inherent risk factors, were controlled in the study, and therefore, the influence of psychosocial factors on MSC's and RSI was not contaminated by these variables.

Other researchers point to other changes that can affect the prevalence of MSCs such as style of work [33], excessive involvement in work [34] and individual abilities to cope with stress at work. Considering those parameters in future analyses would provide a promising confirmation of the recently cited in literature model of a relationship between psychosocial factors and MSCs called the "Cinderella model," which assumes that some psychological features, such as perfectionism, can lead to overuse of lowthreshold motor units in muscles [35, 36]. According to this concept, personal characteristics cause significant job demands to coincide with other demands of personal life (e.g., family ones) and thus make a good life style impossible (e.g., lack of time and motivation for physical exercise) and together they result in stress and an onset of musculoskeletal disorders. The results presented in this paper are a stimulus to conduct such holistic analyses.

In summary, psychosocial factors are a positive predictor of the prevalence of MSCs and RSIs, irrespective of personal factors (age or gender), organizational and physical factors (working hours, repetitive work, force). Thus, those factors should not be neglected by rheumatologists during their routine practice. In an analysis of the etiology of the aforementioned health problems and it should be borne in mind that apart from activity in the private life, adverse psychosocial factors at work also play a role and increase the work-related physical load. The role of prevention of MSDs at the organizational level in the workplace and pro-health behaviors of the workers themselves should not be underestimated.

Acknowledgments This publication was prepared on the basis of the results of a research task carried out within the scope of the first stage of the National Programme "Improvement of safety and working conditions," partly supported in 2008-2010-within the scope of state services - by the Ministry of Labour and Social Policy. The Central Institute for Labour Protection-National Research Institute was the Programme's main co-ordinator.

Open Access This article is distributed under the terms of the Creative Commons Attribution License which permits any use, distribution, and reproduction in any medium, provided the original author(s) and the source are credited.

\section{References}

1. Bongers P, Dewinter C, Kompier M, Hildebrandt V (1993) Psychosocial factors at work and musculoskeletal disease. Scand J Work Environ Health 19:297-312

2. Hoogedoorn W, van Poppel M, Bongers P, Koes B, Bouter L (2000) Systematic review of psychosocial factors at work, private life as risk factor for back pain. Spine 25:2114-2125

3. Häkkänen M, Viikari-Juntura E, Martikainen R (2001) Job experience, work load, and risk of musculoskeletal disorders. Occup Environ Med 58:129-135

4. Bartys S, Burton K, Main C (2005) A prospective study of psychosocial factors and absence due to musculoskeletal disordersimplications for occupational screening. Occup Med 55:375-379

5. Karasek RA, Gordon G, Pietrowsky C, Frese M, Pieper C, Schwartz J et al (1985) Job content questionnaire and user's guide. University of Southern California, Los Angeles

6. Karasek R, Thorell T (1990) Healthy work: stress, productivity, and the reconstruction of working life. Basic Books, New York

7. Linton SJ (2000) A review of psychological risk factors in back and neck pain. Spine 25:1148-1156

8. Windt DAWM, van der Thomas E, Pope DP, de Winter AF, Macfarlane GF, Bouter LM, Silman AJ (2000). Occupational risk factors for shoulder pain: a systematic review. J Occup Environ Med 57:433-442

9. Bongers PM, Kremer AM, ter Laak J (2002) Are psychosocial factors, risks factors for symptoms and signs of the shoulder, elbow, or hand/wrist?: a review of the epidemiological literature. Am J Ind Med 41:315-342

10. Woods V (2005) Work-related musculoskeletal health and social support. Occup Med 55:177-189

11. Hartvigsen J, Lings S, Leboeuf-Yde C, Bakketeig L (2004) Psychosocial factors at work in relation to low back pain and consequences of low back pain; a systematic, critical review of prospective cohort studies. Occup Environ Med, 61. Found on 8 April 2008 at http://www.occenvmed.com/cgi/content/full/61/1/ e2 (03.06.2013)

12. Bongers PM, Ijmker S, van den Heuvel S, Blatter BM (2006) Epidemiology of work-related neck and upper limb problems: psychosocial and personal factors (Part I). and effective interventions from a bio behavioral perspective (Part II). J Occup Rehabil 16:279-302

13. Van den Heuvel SG, van der Beek AJ, Blatter BM, Hoogendoorn WE, Bongers PM (2005) Psychosocial work characteristics in relation to neck and upper limb symptoms. Pain 114:47-53

14. Thorell T (1996) Possible mechanisms behind the relationship between the demand-control-support model and disorders in the 
locomotor system. In: Moon SD, Sauter SI (eds) Psychosocial aspects of musculoskeletal disorders in office work. Taylor \& Francis, Bristol, PA, pp 65-73. Cited after Warren N (2001) Work stress and musculoskeletal disorder etiology: The relative roles of psychosocial and physical risk factors. Work 17:221-234

15. Van Eijsden-Besseling MDF, Peeters FPML, Reijnen JAW, de Lie RA (2004) Perfectionism and coping strategies as risk factor for the development of non-specific work-related upper limb disorders (WRULD). Occup Med 54(2):122-127

16. Malchaire J, Cock N, Vergracht S (2001) Review of the factors associated with musculoskeletal problems in epidemiological studies. Int Arch Occup Environ Health 74:549-557

17. Kuorinka I, Jonsson BG, Kildom A, Vinterberg H, BieringSorensen F, Andersson G, Jorgensen K (1987) Standardised Nordic questionnaire for the analysis of musculoskeletal symptoms. Appl Ergon 18:233-237

18. Sluiter J, Rest KM, Frings-Dresen MHW (2001) Criteria document for evaluating the work-relatedness of upper-extremity musculoskeletal disorders. Scand J Work Environ Health 27(suppl 1):1-102

19. Lawrence RC, Helmick CC, Arnett FC, Deyo RA, Felson DT, Giannini EH, Heyse SP, Hirsch R, Hochberg MC, Hunder GG, Lian MH, Pillemer SR, Steen VD, Wolfe F (1998) Estimates of the prevalence of arthritis and selected musculoskeletal disorders in the United States. Arthritis Rheum 41:778-799

20. Praemer A, Furner S, Rice DP (1992) Musculoskeletal conditions in the United. American Academy of Orthopaedic Surgeons, Park Ridge, IL

21. Devereux JJ, Vlachonikolis IG, Buckle PW (2002) Epidemiological study to investigate potential interaction between physical and psychosocial factors at work that may increase the risk of symptoms of musculoskeletal disorders of the neck and upper limb. Occup Environ Med 59:269-277

22. Walker-Bone K, Reading I, Coggon D, Cooper C, Palmer KT (2006) Risk factors for specific upper limb disorders as compared with non-specific upper limb pain: assessing the utility of a structured examination schedule. Occup Med (Lond) 56(4): 243-250

23. Roquelaure Y, Ha C, Leclerc A, Touranchet A, Sauteron M, Melchior M, Imbernon E, Goldberg M (2006) Epidemiologic surveillance of upper-extremity musculoskeletal disorders in the working population. Arthritis Rheum 55(5):765-778
24. Sillanpaa J, Huikko S, Nyberg M, Kivi P, Laippala P, Uitti J (2003) Effect of work with display units on musculoskeletal disorders in the office environment. Occup Med 53(7):443-451

25. Bugajska J, Konarska M, Tokarski T, Jędryka-Góral A (2007) Zespoły przeciążeniowe w kończynach górnych u pracowników w wybranych grupach zawodowych. Reumatologia 45(6): 355-362

26. Lam N, Thurstone A (1998) Association of obesity, gender, age and occupation with carpal tunnel syndrome, Australia. N Z J Surg 68:190-193

27. de Zwart BCH, Frings-Dresen MHW, Kilbom A (2001) Gender differences in upper extremity musculoskeletal complaints in the working population. Int Arch Occup Environ Health 74:21-30

28. Andersen JH, Kaergaard A, Mikkelsen S, Jensen UF, Frost P, Bonde JP et al (2003) Risk factors in the onset of neck/shoulder pain in a prospective study of workers in industrial and service companies. Occup Environ Med 60:649-654

29. Macfarlane GJ, Hunt IM, Silman AJ (2000) Role of mechanical and psychosocial factors in the onset of forearm pain: prospective population based study. BMJ 321:2911-2918

30. Harkness EF, Macfarlane GJ, Nahit ES (2003) Mechanical and psychosocial factors predict new onset shoulder pain: a prospective cohort study of newly employed workers. Occup Environ Med 60:850-857

31. Jensen C (2003) Development of neck and hand-wrist symptoms in relation to duration of computer use at work. Scand J Work Environ Health 29(3):197-205

32. Lacey RJ, Lewis M, Sim J (2007) Piecework, musculoskeletal pain and the impact of workplace psychosocial factors. Occup Med 57:430-437

33. Feuerstein M, Nicholas RA (2005) Development of a short form of the work style measure. Occup Med 56:94-99

34. Nicholas RA, Feurestein M, Suchday S (2005) Workstyle and upper extremity symptoms: a biobehavioural perspective. J Occup Environ Med 47:352-361

35. Hagg G (1991) Static workloads and occupational myalgia-a new explanation model. In: Anderson PA, Hobart DJ, Danhoff JV (eds) Electromyographical kinesiology. Elsevier Science, Amsterdam, pp 141-144

36. Lundberg U (2002) Psychophysiology of work: stress, gender, endocrine response, and work-related upper extremity disorders. Am J Ind Med 41:383-392 